\title{
Cost-Sharing Arrangements under Sharecropping: Moral Hazard, Incentive Flexibility, and Risk
}

\author{
Avishay Braverman and Joseph E. Stiglitz
}

\begin{abstract}
This paper explains the rationale and describes the characteristics of cost sharing arrangements in rural developing economies, focusing on the risk and incentive properties of alternative cost contracts and on their flexibility-their ability to adapt to environmental changes. It is shown that where labor inputs are difficult to monitor, the rule that cost shares and output shares be equalized will not hold and is not "constrained pareto efficient," and that cost-sharing contracts have a decided advantage over contracts which specify the level of inputs whenever there are asymmetries of information regarding production technology between the landlord and the tenant.
\end{abstract}

Key words: cost sharing, incentive flexibility, information asymmetry, landlord, moral hazard, risk, sharecropping, tenant.

Agricultural output in less developed countries is often produced by peasants working under some form of sharecropping. There is a long tradition of concern that with such contracts peasants will have insufficient incentive to work and to supply other inputs such as fertilizer. Thus, effort (labor supply) and fertilizer inputs will be below the optimum.

Heady pointed out in 1947 that the distortions associated with these other inputs could easily be corrected. If the landlord and tenant share costs to the same extent that they share output, the standard marginal cost equal marginal benefit conditions will be satisfied. (This argument was formalized by Adams and Rask in 1968.) Although the tenant only receives a fraction of the product, he pays only the same fraction of the cost.

In the past decade, a considerable amount of empirical research has, in fact, confirmed

\footnotetext{
The authors are a Senior Economist in the Agriculture and Rural Development Department, the World Bank, Washington D.C.: and a professor, Department of Economics, Princeton University, respectively.

The views presented in this paper are solely those of the authors and do not necessarily reflect the official opinions or views of the World Bank or its affiliates.

The authors wish to thank Robin Lindsey, Franklin Allen, I. J. Singh, Anne Gron, and the anonymous Journal referees for help ful comments on earlier drafts of this paper.

Review was coordinated by Hans P. Binswanger, associate editor.
}

that tenancy contracts generally do have provisions for cost sharing (Ladejinsky, Rao, Rudra; for other sources see Singh, chap. 10). Several of these studies also have shown that there are frequent departures from the simple rule of setting the cost share equal to the output share. These departures are surprising, since the cost share equal to output share rule has both the virtue of simplicity, and, according to Heady, efficiency.

The purpose of this paper is twofold: $(a)$ to provide a rationale for the existence of costsharing arrangements and $(b)$ to analyze the equilibrium cost-sharing rules under sharecropping.

Earlier analyses of sharecropping (Cheung, Stiglitz) asked why, given the seeming inefficiencies associated with sharecropping, was this institutional arrangement so prevalent? They showed, under the assumption that labor input was monitorable, that in fact these contractual arrangements were not inefficient, that the input requirement of labor was (perhaps tacitly) specified in the (implicit) contract between the landlord and tenant. Stiglitz established that under these circumstances a sharecropping contract was in fact equivalent to a linear combination of wage and rental contracts. (This result was subsequently extended by Newbery.) The Stiglitz paper estab- 
lished a similar equivalency theorem for costsharing contracts.

If cost sharing is feasible, then it must be possible for the landlord to observe the level of inputs; and, if the level of inputs is observable, it is at least feasible that the contract specify the level of inputs. ${ }^{1}$ We show that with linear sharecropping contracts (which specify an output share, a cost share, and a fixed payment), the landlord does no worse-but also no better-by specifying the input level than he does by using a cost-sharing contract.

The resolution proposed by Stiglitz for the seeming paradox of the irrelevance of sharecropping was imperfect information: the level of input of labor was not monitorable, at least not without cost. The landlord had to provide an incentive to the worker to work; output is more easily monitorable than input; and, since output and input are correlated, it becomes desirable to base at least part of the workers' compensation on output.

The resolution we propose here for the seeming paradox of the irrelevance of cost sharing is again imperfect information: the optimal input amount is seldom known to the landlord, at least at the time the contract is signed. The optimal level of input changes in response to variations in weather and geographically, according to the nature of the soil and other local conditions. The tenant is thus often in a better position to make decisions concerning the level of inputs. (There is, as it is commonly put these days, an important asymmetry of information between the landlord and the tenant.)

If the changes and differences in circumstances are observable to the tenant but not to the landlord, then the landlord will wish to design a contract which induces the tenant to adjust his input in response to these changes. ${ }^{2}$ A cost-sharing arrangement does this; a fixed quantity contract does not. Nalebuff and Stiglitz have referred to this property of contracts as flexibility.

\footnotetext{
${ }^{1}$ Most formal studies of tenancy contracts ignore this fact. An important exception is the study of Bardhan and Singh. They analyze the interesting problem where the landlord chooses the amount of fertilizer to be bought and the fraction of this cost to be paid by the tenant. The tenant, however, may not use all the fertilizer supplied but may secretly sell some on the open market or, equivalently, use it on his own land (if he has any). The landlord, who realizes that this possibility is available to the tenant, incorporates it into his profit-maximization problem.

${ }^{2}$ All that is really required is that there be differential information between the two. Alternatively, we could have assumed that the costs of writing a contract which specified the level of input corresponding to each state of nature are prohibitive.
}

It is important to emphasize that what is crucial for our argument for cost-sharing contracts is the presence of asymmetries of information concerning the productivity of the monitorable input (fertilizer). There is variability in productivity both over time and across space; productivity is affected not only by weather but also by soil, by the characteristics of the workers and the equipment with which they work, etc. Thus, the terms of the equilibrium (optimal) contract between the landlord and tenant are shown to be critically dependent on both institutional arrangements and certain features of the technology. For instance, the result stated above that cost sharing does no better (but no worse) than specifying input levels directly, simply depends on the existence of symmetric information concerning the technology between the tenant and the landlord. If there is asymmetric information, then at least some cost sharing is desirable. We also provide a set of conditions under which, if the landlord is restricted to choosing either a fixed input contract or a cost-sharing contract, he prefers the latter.

Having explained why cost-sharing rules are employed, we next turn to explain why cost shares may differ from output shares.

In a first-best world, the equal share rule implies an efficient application of inputs. But the very presence of sharecropping represents a significant departure from a first-best world. ${ }^{3}$ As always, it is not obvious, given one important departure from optimality, that there should not be other offsetting departures. There are two important departures from firstbest optimality in sharecropping: (a) the tenant's allocation of effort is not first best, and (b) the tenant must absorb more risk than if there were perfect risk markets.

Since the level of effort cannot be specified (at least perfectly) in the contract, and since increases in the level of effort will increase the landlord's profits, the landlord will seek to induce the tenant to take greater effort. ${ }^{4}$ If fer-

\footnotetext{
${ }^{3}$ Thus, Heady's conclusions were correct, given the model that he employed. Our contention is that, if labor is monitorable, there is no reason to have sharecropping; or if there is sharecropping, it will entail a specification of the level of input of labor (Cheung). We believe that an analysis of sharecropping must take into account the difficulties of monitoring labor inputs.

4 The fact that an increase in some nonlabor input may increase effort has been noted elsewhere (Braverman and Stiglitz, Bell and Zusman, and Mitra). These studies have emphasized the implication this has for the interlinkage of markets. There is a close parallel between the arguments presented here and the standard arguments in optimal tax theory, that commodities which are complements (substitutes) to untaxed commodities should be taxed at a higher (lower) rate. See Atkinson and Stiglitz.
} 
tilizer (or other inputs) are strongly complementary to labor, the landlord may seek to increase the level of effort by increasing the supply of these inputs, i.e., by lowering the cost share of the tenant. Even when there is no incentive effect, if landlords do not charge fixed fees on the use of their land, the cost share may be less than the output share. This is because, by lowering the tenant's cost share, the tenant's output share can be lowered (keeping the tenant at the same level of expected utility), and this will reduce the risks that he faces.

The qualitative results which emerge from our analysis remain valid under a variety of settings. In particular, though in most of the analysis we assume that the tenant works only for one landlord, the results remain valid even if the tenant has outside employment opportunities by which he can supplement his farm income. Similarly, though we focus on the case where the landlord takes the utility level of the tenant as given (either because at lower levels of utility he cannot obtain workers due to the competitiveness of the labor market or because workers cannot survive or are unproductive at lower levels of utility), the results remain valid more generally, also for nonutility-taking equilibria (i.e.; equilibria in which there is an excess supply of potential tenants above their subsistence wage/utility). Likewise, although we focus on the case where the only labor and other input decisions of the tenant are made prior to his observation of the state of nature, the results remain valid when there are actions which can be taken after the state of the nature is known.

\section{The Basic Model}

We shall first outline the basic structure of the model.

\section{Tenant's Problem}

All tenants are assumed to be identical. They lease from the landlord a plot of land whose size is assumed to be technologically fixed. ${ }^{5}$ The tenant determines his labor effort input, $e$. In this section, we also assume that the tenant controls the fertilizer input, $x$, taking the terms

\footnotetext{
${ }^{5}$ This assumption is not critical. See Stiglitz, Braverman and Srinivasan, and Braverman and Stiglitz for an analysis of sharecropping where plot size is endogenous.
}

of the contract as given. The contract terms include his output share, $\alpha$, his cost share, $\beta$, and a fixed payment to the landlord, $\gamma$. The production function is concave in the two factors of production, effort and fertilizer. Output is uncertain because of changing states of nature. For simplicity, we model uncertainty in multiplicative form. Hence, the tenant's income, $Y$, is

$$
Y=\alpha g f(e, x)-\beta P x-\gamma,
$$

where $g$ denotes the non-negative, multiplicative uncertainty factor distributed according to $h(g)$, with mean $E(g)=1$, and $P$ denotes the fertilizer market price; the output price is normalized to 1 . For simplicity, we have assumed at this stage of the analysis that the tenant has a single labor and fertilizer input decision, which is made prior to observing $g$, and that he has no other source of income besides that derived from working on this particular farm. Later, we shall show that neither of these assumptions are crucial.

The tenant maximizes his expected utility of income and labor efforts. ${ }^{6}$ The maximum value will be a function of the terms of the contract, $\alpha, \beta$ and $\gamma$. Formally,

$$
\max _{\{e, x\}} E U[Y(e, x), e] \equiv \hat{V}(\alpha, \beta, \gamma) .
$$

The two first-order conditions can be written as

$$
\begin{aligned}
& f_{x}=\frac{\beta}{\alpha} P / \frac{E U_{1} g}{E U_{1}}=\frac{\beta P}{\alpha \rho}, \text { and } \\
& f_{e}=-\frac{1}{\alpha} / \frac{E U_{1} g}{E U_{2}}=-\frac{1}{\alpha \rho} \cdot \frac{E U_{2}}{E U_{1}},
\end{aligned}
$$

where $\rho \equiv E U_{1} g / E U_{1}$ is the risk factor satisfying $0<\rho<1$ since COV $\left\{U_{1}(g), g\right\}<0$. $^{7}$ For risk-neutral tenants, $\rho=1$, and for infinitely risk-averse tenants, $\rho=\min g$.

Since the latter part of this paper focuses on the relationship between the cost share and the output share, it is natural to define

$$
\delta=\frac{\beta}{\alpha}
$$

\footnotetext{
${ }^{6}$ The indirect utility function (2) is derived by solving the firstorder conditions (3a) and (3b) for $e$ and $x$ as functions of $\alpha$ and $\beta$, and by substituting both into the utility function; $U$ is assumed to be a standard, well-behaved, risk-averse, and effort-averse utility function, with $U_{1}(Y, e)>0, U_{2}(Y, e)<0, U_{11}(Y, e)<0, U_{22}(Y, e)$ $>0$.

${ }^{7}$ The larger $g$ is, the larger is output $g f$; hence, the larger is the tenant's income, and by the concavity of $U$, the smaller is the marginal utility of income.
} 
Thus, Heady's hypothesis that tenancy contracts should (do) entail cost shares equal to output shares is equivalent to the hypothesis that $\delta=1$.

We now rewrite the tenant's income, his expected utility, and his first-order condition for input $x$, as a function of $\alpha, \delta$, and $\gamma$. Thus,

$$
\begin{gathered}
Y=\alpha[g f-\delta P x]-\gamma, \\
V(\alpha, \delta, \gamma) \equiv \hat{V}(\alpha, \alpha \delta, \gamma),
\end{gathered}
$$

and ( $3 \mathrm{a})$ becomes

$$
f_{x}=\frac{\delta P}{\rho} .
$$

Notice from equation (4) that $\delta P / \rho$ acts as the internal price of the input; that is, the tenant purchases the same amount of fertilizer that he would if he were risk neutral and faced a price of $\delta P / \rho$.

The first-order conditions are solved to yield the inputs supplied as functions of $\alpha, \delta$, and $\gamma$ :

$$
\begin{aligned}
& e=e(\alpha, \delta, \gamma), \\
& x=x(\alpha, \delta, \gamma),
\end{aligned}
$$

and mean output

$$
Q(\alpha, \delta, \gamma)=f[e(\alpha, \delta, \gamma), x(\alpha, \delta, \gamma)] .
$$

Though the landlord cannot directly control effort (he still may control directly the input of fertilizer), he knows that he will affect the tenant's decisions by altering the terms of the contract. How he does this is the focus of the remaining analysis.

We assume that the tenant has an alternative occupation yielding a given expected utility level $\bar{V}$. Thus, in order to accept a tenancy position, he requires that $V(\alpha, \delta, \gamma) \geq \bar{V}$. (For the analysis below, it makes no difference how $\bar{V}$ is determined, i.e., whether labor markets are competitive, so that the landlord cannot obtain tenants at any utility level below $\bar{V}$, or whether the landlord is a monopsonist, and $\bar{V}$ is the subsistence level of utility.) We assume that the utility constraint is binding, but this assumption too is not critical, as we shall see below. $^{8}$

\footnotetext{
${ }^{8}$ Such an equilibrium (explored in Stiglitz) is accordingly sometimes referred to as a utility equivalent contract equilibrium. See Braverman and Stiglitz and Braverman and Srinivasan for further discussions of both utility equivalent and nonequivalent contract equilibria in rural developing economies. It is important to emphasize that it makes no difference whether we formulate the problem as above or as maximizing the expected utility of the tenant, subject to a constraint providing the landlord with a given expected
}

\section{The Landlord's Problem}

The landlord's problem is to find that contract (defined by $\alpha, \delta$, and $\gamma$ ) yielding tenants an expected utility $\bar{V}$ which maximizes his expected utility. The landlord takes into account the responses of the tenant to changes in the contract. For simplicity we assume that the landlord is risk neutral and therefore maximizes expected profits. Since $E g=1$, we can write the landlord's problem as

(8) $\max _{\{\alpha, \delta\}} \Pi=(1-\alpha) f(e, x)$

$$
-(1-\alpha \delta) P x+\gamma
$$

subject to

$$
V(\alpha, \delta, \gamma)=\bar{V} \text {. }
$$

The landlord's controls are the output share, $\alpha, \delta$, the ratio of the cost share, $\beta$, to output share, $\alpha$, and the fixed fee, $\gamma$.

\section{A Basic Equivalence Result}

Why are there cost-sharing contracts? For there to be cost-sharing contracts, inputs must be observable; and if inputs are observable, the landlord could just as well simply specify the level of inputs. In this section, we show that if he does this, he can do no better and no worse than he can do with a cost-sharing contract: the two are in effect equivalent in a world where landlords and tenants possess identical information on production technology.

To see this, we will first describe the behavior of the tenant when faced with a particular input level specified by the landlord. We then show that for any contract which specifies a particular level of input of fertilizer $x$, there exists a corresponding contract which leaves the input of fertilizer to the discretion of the tenant, but in which his income, effort, and fertilizer input in every state of nature is identical; moreover, the landlord's income in every state of nature is also identical.

When $x$ is specified, tenants simply set

$$
\alpha E U_{1} f_{e} g=E U_{2} .
$$

Consider any linear share contract $\left[\alpha^{*}, \beta^{*}\right.$, $\gamma^{*}$. Associated with it there will be an equilib-

return to his land. Our analysis is simply concerned with characterizing the set of (locally) efficient contracts, given the information constraints. 
rium level of input, $x^{*}$. Consider the new contract specifying the input level

$$
\hat{x}=x^{*}
$$

with

$$
\begin{aligned}
& \hat{\alpha}=\alpha^{*} \text { and } \\
& \hat{\gamma}=\gamma^{*}-\left(1-\beta^{*}\right) P x^{*} .
\end{aligned}
$$

That is, the new contract has the same output share, and the fixed payment is adjusted to make the tenant pay the same fixed fee inclusive of his expenditures on inputs. Clearly, in each state of nature for each level of effort, the income of the tenant will be the same; therefore, the tenant will choose the same level of effort, and, hence, output in each state of nature will be the same. Since the share of output is the same, and because the fixed payment has been adjusted to take account of the differences in expenditures on fertilizer, the expected profit of the landlord and the expected utility of the tenant are identical with the two contracts. ${ }^{9}$

Thus, we have established an equivalence result similar to that in earlier literature on risk and sharecropping (Stiglitz, Newbery). There it was shown that by mixing rental and wage contracts, tenants could reduce their risk in the same way that sharecroppers reduce risk. That analysis made it clear that one could not view sharecropping as simply a means by which landlords and tenants shared risks. To understand sharecropping, one must explicitly consider incentives.

The analysis here demonstrates that one cannot understand the role of cost sharing using a model in which the landlord and the tenant have identical information concerning the input of fertilizers. In the next section, we show how asymmetric information provides a natural rationale for the use of cost-sharing contracts.

\section{Cost Sharing, Incentive Flexibility, and Asymmetric Information}

Assume now that there is some aspect of the technology which varies, say, with the

\footnotetext{
9 This argument establishes that corresponding to every costsharing contract, there exists a contract specifying the level of input which yields equivalent outcomes; the converse result, that corresponding to every contract that specifies a particular level of fertilizer input, there exists a corresponding equivalent costsharing contract, requires only the standard convexity assumptions. If these assumptions fail, it implies that input specification contracts dominate cost-sharing contracts.
}

weather or the soil and which affects the productivity of an input such as fertilizer. Thus, our production function is now

$$
Q=f(e, u x) g,
$$

where $u$ is a variable (normalized to have mean of unity) which is observable to the tenant but not to the landlord. Moreover, the tenant can observe $u$ before making his decision concerning the input of fertilizer. In the firstbest world of perfect information and perfect insurance (risk neutrality), in each state (or at each location) the value of the marginal product of an extra unit of fertilizer is set equal to its price:

$$
u f_{x}=P \text {. }
$$

However, with cost sharing and sharecropping under risk aversion, (13) becomes

$$
\alpha u \rho f_{x}=\beta P \text {. }
$$

Thus, $x$ will still vary with $u$. When $u$ is higher, $x$ will normally be higher.

We wish, however, to establish two further results demonstrating the advantages of costsharing contracts over contracts with prespecified inputs.

First, if the landlord is restricted to either a fixed input contract or a cost-sharing contract and labor (effort) is perfectly inelastically supplied, he prefers the latter provided tenants' risk aversion is not too sensitive to changes in $u$. To see this, we show how the optimal fixed input contract can be improved upon. Let $\{\hat{\alpha}$, $\hat{x}, \hat{\gamma}\}$ denote this contract. Now set $\alpha^{*}=\hat{\alpha}$, set $\beta^{*}$ such that $x^{*}=\hat{x}$, so that average input with cost sharing is equal to $\hat{x}$, and

$$
\gamma^{*}=\hat{\gamma}+P \hat{x}\left(1-\beta^{*}\right) \text {. }
$$

Clearly, tenants are better off with this contract, since they could set $x^{*}=\hat{x}$, for all $u$, and their expected utility would be the same as with the fixed input contract. But since in general $\hat{x} \neq x^{*}$ for some $u$, they choose an input level which increases their expected utility.

The tenant sets $x$ by (14). Hence, provided $\rho$ does not decrease too rapidly as $u$ increases, he allocates more fertilizer when $u$ is high (productivity is high). But if he allocates more fertilizer when it is more productive, average output will be increased; since the sum of the fixed payments by the tenant plus his expenditures on fertilizer are the same under the two regimes, and $\alpha$ is the same but average output is higher, the landlord is clearly better off. 
Second, in general, even with variable effort, a mixed contract involving some degree of cost sharing dominates a fixed input contract $\{\hat{\alpha}, \hat{x}, \hat{\gamma}\}$. Again, we can show this by construction. We define a mixed contract as follows. We specify a minimum level of input, $\hat{x}$; the tenant is reimbursed a fraction $\left(1-\beta^{*}\right)$ of expenditures in excess of $\hat{x}$. The fixed input contract can be viewed as one in which $1-\beta^{*}$ $=0$. Now, set $x^{*}=\hat{x}, \alpha^{*}=\hat{\alpha}$, but increase the reimbursement share and simultaneously increase $\gamma$ to keep expected utility constant. It can be shown that, in general, the optimal contract will entail some degree of cost sharing, i.e., $1>\beta^{*}>0$. The reason for this is again that cost-sharing contracts improve the efficiency of allocation of inputs-more inputs are applied when they are most productive. The tenant's private purchases of inputs, only partially compensated by the landlord, impose greater risk on the tenant, but he will only undertake the increased input if the gains in his share of the output more than offset the increased risk which he must bear; a fortiori, the landlord is better off because he is indifferent to risk and only gains from the increased output. The only case in which such a costsharing contract might not be desirable is if the increased input of fertilizer is a substitute for effort and the farmer is led to decrease his labor supply so much that output is actually reduced as a result of the increased input of fertilizer. This seems an unlikely possibility. ${ }^{10}$

\section{Characterization of Optimal Cost-Sharing Contracts}

In the previous section, we provided an explanation for cost-sharing contracts; we showed that such contracts had a distinct advantage over contracts in which the landlord simply specified the level of input, or equivalently, provided the input to the tenant.

It would be a straightforward matter for us now to specify the optimal contract between the landlord and his tenant. In general, such a contract would not be a linear contract, of the form described earlier, e.g., by equation (1). Rather, the income of the tenant would be specified as a quite complicated function of

\footnotetext{
${ }^{10}$ The critical condition for establishing this result is that a compensated increase in incentives increases output:

$$
\left.\left(\frac{d e}{d \beta}\right)\right|_{\bar{v}} f_{e}+\left.\left(\frac{d x}{d \beta}\right)\right|_{\bar{v}} f_{x} u<0 .
$$
}

both observable variables, the level of output and the level of input of fertilizer:

$$
Y=Y(Q, x), Y_{1}>0, Y_{2}>0,
$$

increasing in both output and input but not in general linear; and, indeed, there may be important interaction terms, with the marginal output share depending on the level of input. Though the differential equations describing these optimal "compensation" schemes are easy to write down, they are hard to interpret.

We have a further objection to this approach: the kinds of contracts observed in practice are relatively simple. They are seldom nonlinear; even when they are nonlinear, they remain simple, e.g., they are piece-wise linear (as in our example above, where the landlord reimbursed a given fraction of expenditures above a given level); and they virtually never employ interaction terms. Indeed, they often do not seem to exhibit the variability from circumstance to circumstance that theory would predict; it seems implausible that the optimal contract (as we have modeled the problem) would just happen to entail a $50 \%$ crop share in the wide variety of circumstances in which that share seems to be employed.

Thus, it seems to us as theorists that the problem to focus on is not what the optimal nonlinear contract looks like-for these are not the kinds of contracts observed-but on why we do not see these more complicated contracts. Some reasons suggest themselves: whenever usage (as opposed to purchase) of inputs cannot be observed, arbitrage opportunities are opened up whenever marginal input costs differ across farms; the tenant on the farm where the landlord pays a larger share of the costs will find it profitable to purchase the input for resale to the farm where the landlord pays a low share. With heterogeneity among farms and with nonlinear contracts, marginal input costs will always differ across farms. ${ }^{11}$ The same arguments apply if the physical output of a farmer cannot be monitored, but only the surplus which he attempts to market. Then, only linear contracts will be feasible, and all contracts within a region (for a given crop) will have to have the same output share.

\footnotetext{
${ }^{11}$ It should be clear that the possibility of arbitrage across farms not only imposes restrictions on the form of the sharecropping contracts but also on the range of terms that will be observed within a region. This may give rise to multiple Nash equilibria. The analysis of this paper can then be thought of as characterizing the set of pareto-efficient Nash equilibria.
} 
Transaction costs (including the costs of designing such contracts) provide a second explanation. ${ }^{12}$

Regardless of the explanation for why linear rather than nonlinear contracts are employed, it seems to us more useful to characterize what linear contracts look like rather than to characterize what some (unobserved) nonlinear contract might look like.

For reasons of analytical simplicity, we return to the model presented in the first section, where there is symmetric information concerning technology (application of fertilizers), though there continues to be asymmetry of information concerning labor inputs. The qualitative results will continue to hold even in the case of some asymmetries of technological information, provided they are not too large.

We begin our analysis by considering the relationship between the output and cost share in contracts in which the fixed fee, $\gamma$, is set equal to zero. ${ }^{13}$ There is some debate about whether this case, or the case described in the next subsection, where $\gamma$ is set optimally, is the more relevant. Observed contractual relationships seldom seem to involve fixed transfers between the landlord and the tenant. On the other hand, there are several contractual provisions which may serve as a substitute; for instance, if the landlord provides a certain minimal level of the input, $x$, it is equivalent to $\gamma<0$; or if the tenant is required to purchase certain inputs from the landlord at above market prices, it may be equivalent to a contract with $\gamma>0$. Such problems of interpretation arise whenever there is some interlinkage of contracts, including the interlinkage of credit and land contracts (see Braverman and Stiglitz).

In any case, it turns out that the qualitative results for the two cases are similar, and it is

\footnotetext{
${ }^{12}$ See Bell and Zusman, Hurwicz and Shapiro, and Allen for other explanations. At the same time, we note an important qualification to this research strategy: whatever the factor is that plays a central role in determining that linear, rather than nonlinear contracts, are employed, it may in turn also play an important role in determining the relationship between cost share and output share. Indeed, if simplicity (transactions cost) provides an important part of the explanation for the widespread use of the $50 \%$ output share rule, it also provides part of the explanation for the employment of a $50 \%$ cost-sharing rule. In this context, the observed deviations from this rule seem all the more remarkable. This suggests that the considerations with which we are concerned here are not only present, but in these circumstances may be important.

${ }^{13}$ It should be noted that the equivalency result does not hold when $\gamma=0$. In this case, a contract with some cost sharing dominates one with none.
}

easier to see what is going on by first examining the case where $\gamma$ is set equal to zero.

\section{Optimal Cost Sharing with $\gamma=0$}

From the utility equivalence constraint we can derive the relation $\alpha(\delta)$ which implies the pairs of output share and cost share, maintaining the tenant at utility $\bar{V}$. Substituting $\alpha(\delta)$ into (8) we obtain [using (6) and (7)]

$$
\text { (15) } \begin{aligned}
\max _{\delta} \Pi(\delta)=[1-\alpha] Q(\alpha, \delta) \\
-(1-\alpha \delta) P x(\alpha, \delta),
\end{aligned}
$$

where $\alpha=\alpha(\delta)$. From the first-order condition of (15) we can derive the cost-sharing rules. It is the solution to

$$
\begin{array}{r}
\pi_{\delta}=\left.(-Q+\delta P x) \frac{d \alpha}{d \delta}\right|_{\bar{V}}+\alpha P x \\
\text { direct effect } \\
+\left.\left\{(1-\alpha) Q_{x}-(1-\alpha \delta) P\right\} \frac{d x}{d \delta}\right|_{\bar{V}} \\
\text { indirect effect on fertilizer input } \\
+\left.(1-\alpha) Q_{e} \frac{d e}{d \delta}\right|_{\bar{V}}=0 \\
\text { indirect effect on effort }
\end{array}
$$

where

$$
\text { (17) }\left.\frac{d x}{d \delta}\right|_{\bar{V}}=\frac{\partial x}{\partial \delta}+\left.\frac{\partial x}{\partial \alpha} \frac{d \alpha}{d \delta}\right|_{\bar{V}},\left.\frac{d e}{d \delta}\right|_{\bar{V}}
$$

is similarly defined, and

$$
\begin{aligned}
\left.\frac{d \alpha}{d \delta}\right|_{\bar{V}}= & -\frac{\partial V / \partial \delta}{\partial V / \partial \alpha} \\
= & \frac{\alpha E U_{1} P x}{E U_{1}(g f-\delta P x)}=\frac{\alpha z}{\rho-\delta z},
\end{aligned}
$$

where $z=P x / f$ denotes the ratio of the value of the input of fertilizer to (the expected value of) output.

$$
\text { At } \delta=1,(\alpha=\beta) \text {, }
$$

$$
\begin{aligned}
\pi_{\delta} & =\frac{\alpha Q z(-1+\rho)}{\rho-z} \\
& +\left.(1-\alpha) P\left(\frac{1}{\rho}-1\right) \frac{d x}{d \delta}\right|_{\bar{V}} \\
& +\left.(1-\alpha) Q_{e} \frac{d e}{d \delta}\right|_{\bar{V}}
\end{aligned}
$$

Equation (19) has several direct implications:

(a) If there are no incentive effects $\left(d e /\left.d \delta\right|_{\bar{V}}\right.$ 
$=0)$ and tenants are risk neutral $(\rho=1)$, then the first-order condition of (19) holds and $\alpha=$ $\beta$. These are the conditions under which Heady's conclusion, that the cost share should equal the output share, is valid.

(b) If there are no risk effects $(\rho=1)$, then

$$
\beta \lessgtr \alpha \text { as }\left.\frac{d e}{d \delta}\right|_{\bar{V}} \lessgtr 0 \text { if } \pi_{\delta \delta}<0 .{ }^{14}
$$

We might expect a (compensated) increase in the effective price of fertilizer to decrease the utilization of fertilizer and the reduction in the input of fertilizer, in turn, to reduce the marginal return to effort, and thus the level of effort. In that case, $\beta<\alpha$, to encourage effort, we subsidize the input of fertilizer. It is, of course, possible for the opposite to occur, for instance, if a decrease in the utilization of fertilizer increases the marginal return to effort. Under the hypothesis that the utility function is separable, we can show that

$$
\left.\operatorname{sign}\left(\frac{d e}{d \delta}\right)\right|_{\bar{v}} \sim \operatorname{sign}\left(\frac{\epsilon}{1-z}+\frac{f_{e x} e}{f_{x x} x}\right),
$$

where $\epsilon \equiv f_{e} e / f$ is the elasticity of output with respect to effort.

(c) If there are no incentive effects then again we obtain $\beta<\alpha$, since the first term of (19) is negative (provided the risk effect is not too large, i.e., $\rho>z$ ), and the second term is normally also negative.

There is a simple intuition behind this result. When the landlord increases $\delta$, he forces the tenant to bear greater risks because the expenditures on inputs are fixed costs. Even at $\delta=1$, because of his risk aversion, the tenant has purchased less than the first-best level of inputs. Because the landlord is risk neutral, a contract in which he bears more of the risk, and in which he simultaneously encourages the tenant to use more inputs, constitutes a pareto improvement from the equal shares rule.

For constant relative risk aversion, we can obtain the stronger result that as risk aversion increases, $\delta$ is monotonically reduced, so that the landlord decreases his cost share relative to his output share. (See details in BravermanStiglitz.)

\footnotetext{
is All that we have really established from (19) is that at $\delta=1$, the landlord can increase his expected return and still obtain tenants by lowering $\delta$. If $\Pi(\delta)$ is a globally concave iunction of $\delta$, then this local analysis is sufficient to ensure that the globally optimal level of $\delta$ is less than unity.
}

\section{Optimal Cost Sharing with $\gamma \neq 0$}

The analysis can be extended to more general contractual arrangements with $\gamma \neq 0$ without changing the qualitative results. Recall that the contract is chosen to $\max _{(\alpha, \delta, \gamma)}$ II subject to $V(\alpha$, $\delta, \gamma) \geq \bar{V}$. As before, we can write the inputs $x$ and $e$ and the mean output, $Q$, as a function of the parameters $\alpha, \delta$, and $\gamma$. Manipulation of the first-order conditions yields

$$
\text { (20) } \begin{aligned}
\Pi_{\delta}=\left.(1-\alpha) f_{e}\left(\frac{d e}{d \delta}\right)\right|_{\bar{v}} & \\
+\left.\left(\frac{d x}{d \delta}\right)\right|_{\bar{V}}\left\{(1-\alpha) f_{x}\right. & -P(1-\alpha \delta)\} \\
+ & \left\{\alpha P x+\left.\frac{d \gamma}{d \delta}\right|_{\bar{v}}\right\},
\end{aligned}
$$

where now the compensated derivatives are defined by

$$
\text { (21) } \begin{aligned}
\left.\frac{d e}{d \delta}\right|_{\bar{\nu}} \equiv \frac{\partial e}{\partial \delta}+\frac{d \gamma}{d \delta} & \left.\right|_{\bar{V}} \cdot \frac{\partial e}{\partial \gamma},\left.\left(\frac{d x}{d \delta}\right)\right|_{\bar{\nu}} \\
& \equiv \frac{\partial x}{\partial \delta}+\left.\frac{d \gamma}{d \delta}\right|_{\bar{V}} \frac{\partial x}{\partial \gamma},
\end{aligned}
$$

i.e., the compensation occurs through the adjustment of the fixed fee, where $-d \gamma /\left.d \delta\right|_{\vec{V}}=$ $\alpha P x$. Furthermore, it can be shown that, as before, at $\alpha=\beta,(\delta=1)$, the tenant sets

$$
f_{x}=\frac{P}{\rho} .
$$

Hence, (20) can be rewritten as $\delta=1$ as

$$
\begin{aligned}
\pi_{\delta}=(1-\alpha)\left[\left.f_{e} \frac{d e}{d \delta}\right|_{\bar{v}}\right. & \\
& \left.+\left.f_{x} \frac{d x}{d \delta}\right|_{\bar{v}}(1-\rho)\right]
\end{aligned}
$$

At $\delta=1(\alpha=\beta), \pi_{\delta}$ will not, in general, be equal to zero (except if there are no risk effects, i.e., $\rho=1$, and no incentive effects, i.e., $d e /\left.d \delta\right|_{\dot{V}}=0$ ). This implies that, in general, the equilibrium contract will entail $\delta \neq 1(\alpha \neq \beta)$.

Under the normal presumption that a compensated increase in the cost share will lead to a decrease in input, and, if effort and fertilizer are complements also to a decrease in effort, it is apparent that for (20) to be equal to zero,

$$
(1-\alpha) \frac{\delta}{\rho}-(1-\alpha \delta)<0,
$$


which implies that

$$
\delta<\frac{\rho}{1-\alpha(1-\rho)}<1
$$

i.e., the cost share should be less than the output share.

\section{Robustness of Results}

In our earlier discussion, we employed three assumptions: (a) the tenant had no outside employment opportunities; $(b)$ the level of utility of the tenant was taken as given at $\bar{V}$; and $(c)$ the tenant's effort decisions were made prior to knowing the state of the weather $g$. We show here why none of these assumptions are critical.

(a) Outside employment opportunities. Assume the tenant can obtain employment elsewhere at a wage $w$. Denote by $e_{2}$ his labor supply on the outside market and by $e_{1}$ his labor supply on the farm. Then his income is

$$
\begin{aligned}
& Y=\alpha g f\left(e_{1}, x\right)-\beta x-\gamma \\
& +w e_{2}=Y\left(e_{1}, e_{2}, x\right) \text {, }
\end{aligned}
$$

and he maximizes

$$
E U\left(Y, e_{1}+e_{2}\right) \text {. }
$$

We derive, from (27), effort and input supply functions just as before:

$e_{i}=e_{i}(\alpha, \delta, \gamma, w), i=1,2$,

$$
x=x(\alpha, \delta, \gamma, w),
$$

and the equilibrium contract is still characterized by the solution to

$$
\max \Pi \text { s.t. } V \geq \bar{V} \text {. }
$$

The analysis proceeds just as before, though the value of the compensated derivatives will undoubtedly be affected by the availability of outside work opportunities, the presumption that $\beta<\alpha$ remains. $^{15}$

\footnotetext{
${ }^{15}$ This result holds whether the tenant must make his outside employment commitments prior to knowing $g$ or not. It also holds whether $e_{2}$ is or is not observable; though if it is, and the $e_{2}$ decision is made prior to knowing $g$, then the contract will specify a level of $e_{2}$. The assumption of outside labor opportunity actually simplifies the calculations of the value of the compensated elasticities, if $w$ is fixed. Assume, for instance, that $g=1$. Then the first-order conditions are
}

$$
E U_{1} \alpha g f_{e}=-E U_{2}=E U_{1} w, \text { and } E U_{1} \alpha g f_{x}=E U_{1} \beta P,
$$

implying if $\rho=1$,

$$
\alpha f_{e}=w, f_{x}=P \delta,
$$

(b) Binding utility constraint. Earlier, we assumed that the landlord had to provide a level of utility to the tenant (with or without outside employment opportunities) at least equal to $\bar{V}$; $\bar{V}$ could be interpreted in two different ways. It is either the subsistence utility level, or the competitive equilibrium level, below which the landlord could not obtain tenants. ${ }^{16} \mathrm{We}$ further assumed that the constraint was binding. There are circumstances under which the constraint may not be binding. This will be the case if there is unemployment and it does not pay the landlord to pish tenants down to the subsistence constraint due to the decline in their output. Then, when the landlord increases $\delta$, he does not have to compensate for the increase in $\delta$ by increasing $\alpha$ or $\gamma$. Hence, at $\delta=1,(19)$ becomes

$$
\begin{aligned}
\pi_{\delta}=\alpha P x+(1 & -\alpha) p\left(\frac{1}{\rho}-1\right) \\
& \cdot \frac{d x}{d \delta}+(1-\alpha) Q e \frac{d e}{d \delta}
\end{aligned}
$$

where the derivatives are not compensated derivatives. While it remains plausible that an increase in $\delta$ reduces $x$ and thus also reduces $e$, now the disadvantages of increasing $\delta$ have to be set against the advantage of the increased revenue $(\alpha P x)$. It is still unlikely that $\pi_{\delta}=0$ at $\delta=1$, but there is less of a presumption that $\delta<1(\beta<\alpha)$ than in the utility binding case.

(c) Timing of actions. In the previous section we showed that the possibility that fertilizer could be applied after some information concerning the weather was known (to the tenant) made cost-sharing arrangements desirable. What was critical to that result was the existence of some asymmetry of information between the landlord and tenant, an assumption which we view to be plausible; but the result is robust to a variety of assumptions concerning the precise timing of inputs. Assume, for instance, that some inputs of labor and fertilizer are provided before $u$ is known

and (in the case of sharecropping contracts which include also fixed a fee) independent of the form of the utility function:

$$
\left.\frac{d e}{d 6}\right|_{\dot{V}}=\frac{-P f_{e x}}{f_{e e} f_{x x}-f_{e x 2}} \lessgtr 0 \text { as } f_{e x} \gtrless 0 .
$$

${ }^{16}$ Elsewhere, we have detailed how one can solve for the competitive equilibrium level of $\bar{V}$. In a market equilibrium, of course, each landlord takes $\bar{V}$ as given (just as in the standard competitive theory, each firm takes the wage it must pay as given). See Braverman and Stiglitz. 
and some after. Denoting the former by subscript 1 and the latter by subscript 2 , the tenant's behavior can be described by a simple dynamic programming problem. Assuming linear sharecropping contracts $\{\alpha, \beta, \gamma\}$, and given $e_{1}, x_{1}$, and $u$, he chooses $e_{2}$ and $x_{2}$ to maximize his expected utility, obtaining

$$
\begin{aligned}
e_{2} & =e_{2}\left(u ; e_{1}, x_{1} ; \alpha, \beta, \gamma\right), \\
x_{2} & =x_{2}\left(u ; e_{1}, x_{1} ; \alpha, \beta, \gamma\right), \text { and } \\
\tilde{U} & =\tilde{U}\left(u, x_{1}, e_{1} ; \alpha, \beta, \gamma\right) .
\end{aligned}
$$

He then chooses $x_{1}$ and $e_{1}$ to maximize $\tilde{E} U$, yielding

$$
e_{1}=e_{1}(\alpha, \beta, \gamma), x_{1}=x_{1}(\alpha, \beta, \gamma) .
$$

These functions may be substituted back into (29) to obtain input supply functions which are simply functions of $u, \alpha, \beta$, and $\gamma$.

The equilibrium contract then maximizes the landlord's expected return, subject to the tenant's obtaining a given level of expected utility. The analysis proceeds exactly as before.

All that is critical to the result concerning the desirability of some use of cost sharing is that the tenant make some adjustments to his input of fertilizer after $u$ is observed. Adjustments in effort supply will of course affect the magnitude of the return to adjusting the input of fertilizer, but, in general, there will be some return to adjusting the input of fertilizer to changed circumstances. (Note that if $u$ is constant, but (a) tenants can work outside, (b) $w$ is variable, and $(c)$ there is some adjustment of the labor supply on the farm after $w$ is known, then cost sharing will also be desirable; the changed labor input will change the optimal level of fertilizer input. ${ }^{17}$ )

\section{Concluding Remarks}

In recent years there has been considerable interest in the analysis of incentive problems, situations in which one individual (the landlord, lender, employer), generally referred to

\footnotetext{
17 To repeat, what is critical for the equivalence result is that there be symmetric information between the landlord and the tenant. If, for instance, there is an outside labor market, and some fertilizer is applied after either outside wages (employment opportunities) or the state of nature become known, then a contract specifying levels of input (at each value of $w$ or each value of $u$ ) can do as well as a cost-sharing contract; such contracts are feasible under the assumption of symmetric information, but not under the assumption of asymmetric information.
}

as the principal, seeks to affect the actions of another (the tenant, borrower, employee), generally referred to as the agent, by appropriately choosing the terms of the contract between them. The interests of the two are assumed to differ, and it is assumed prohibitively expensive for the principal to monitor directly the actions of the agent. ${ }^{18}$ Thus, the principal must base his compensation scheme on the outputs (or other observable variables) of the agent. The prototype of this kind of relationship is that between the landlord and his tenant. In this "new view," sharecropping is not seen just as an inefficient anachronism (this last characterization is unjustifiably attributed to Marshall). ${ }^{19}$ Rather, sharecropping contracts are viewed as playing an important role both in sharing risks and providing incentives.

Most of the earlier analysis of the principalagent relationships have focused on situations where the agent has a single variable (effort) under his control. But in most situations, the tenant may have several variables-effort, choice of technique, level of other inputswhich he can determine. The terms of the contract affect all of these decisions. Analyses focusing on a single decision may accordingly be misleading. In addition, the landlord must consider the impact of other contracts on the tenant's control variables. This may lead to the interlinking of agrarian contracts. (See Bardhan, Bell and Zusman, Braverman and Srinivasan, Braverman, Braverman and Guasch, Mitra, Binswanger and Rosenzweig.)

In addition, the recent literature on principal-agent problems has stressed the importance not only of the risk and incentive properties of alternative contractual arrangements but also their flexibility, their ability to adapt to changes in the environment. The discussion in this paper can be viewed as an important application of all these general principles of principal-agent problems.

In particular, we have shown that in the relevant cases where labor inputs are difficult to monitor Heady's rule that cost shares and out-

\footnotetext{
18 It is in that sense that these problems differ from the team theory problems.

19 Marshall recognized the importance of share contracts in a world dominated by market imperfections and the absence of certain markets. The so-called "Marshallian School" of sharecropping seems to have originated out of a technical footnote rather than the main text. (See Bliss and Stern, chap. 3, and Jaynes on this point.)
} 
put shares be equalized will hold, in general, only in the absence of risk and incentive effects. Further, we have shown that costsharing contracts have a decided advantage over contracts which specify the level of inputs whenever there are asymmetries of information regarding production technology between the landlord and the tenant.

\section{[Received December 1983; final revision received April 1985.]}

\section{References}

Adams, D. W., and N. Rask. "Economics of Cost-Share Leases in Less Developed Countries.' Amer. J. Agr. Econ. 50(1968):935-42.

Allen, Franklin. "On the Fixed Nature of Sharecropping Contracts." Econ. J. 95(1985):30-48.

Atkinson, A., and J. E. Stiglitz. Lectures on Public Economics. New York: McGraw-Hill Book Co., 1980.

Bardhan, P. K. "Interlocking Factor Markets and Agrarian Development: A Review of Issues." Oxford Econ. Pap. 32(1980):82-98.

Bardhan, P. K., and N. Singh. "A Note on Cost Sharing and Incentives in Sharecropping." Preliminary draft, University of California, Berkeley, 1982.

Bell, C., and P. Zusman. "A Bargaining Theoretic Approach to Crop Sharing Contracts." Amer. Econ. Rev. 66(1976):578-88.

- "On the Interrelationship of Credit and Tenancy Contracts.' Washington DC: World Bank, Development Research Center, March 1980.

Binswanger, Hans P., and Mark R. Rosenzweig, eds. Contractual Arrangements, Employment and Wages in Labor Markets in Asia. New Haven CT: Yale University Press, 1984.

Bliss, C. J., and N. H. Stern. Palanpur-Studies in the Economy of a North Indian Village. New Delhi, India: Oxford University Press, 1981.

Braverman, A., and J. L. Guasch. "Capital Requirements, Screening and Interlinked Sharecropping and Credit Contracts.' J. Develop. Econ. 14(1984):359_ 74.

Braverman, A., and T. N. Srinivasan. "Credit and Share- cropping in Agrarian Societies." J. Develop. Econ. 9(1981):289-312.

Braverman, A., and J. E. Stiglitz. "Moral Hazard, Incentive Flexibility and Risk: Cost Sharing Arrangements Under Sharecropping.' Mimeographed. Washington DC: The World Bank, 1982.

Braverman, A., and J. E. Stiglitz. "Sharecropping and the Interlinking of Agrarian Markets." Amer. Econ. Rev. 72(1982):695-715.

Cheung, Steven N. The Theory of Tenancy. Chicago: University of Chicago Press, 1969.

Heady, E. "Economics of Farm Leasing Systems." $J$. Farm Econ. 29(1947):659-78.

Hurwicz, L., and L. Shapiro. "Incentive Structures Maximizing Residual Gains under Incomplete Information." Bell J. Econ. 9(1978):180-91.

Jaynes, D. J. "Economic Theory and Land Tenure." Rural Labor Markets in Asia: Contractual Arrangements, Employment and Wages, ed. H. Binswanger and M. Rosenzweig. New Haven CT: Yale University Press, 1984.

Ladejinsky, W. "Agrarian Reform in India." The Selected Papers of Wolf Ladejinsky-Agrarian Reform as Unfinished Business, ed. L. Y. Walinsky. New York: Oxford University Press, 1977.

Marshall, A. Principles of Economics. London: Macmillan \& Co., 1920.

Mitra, P. "A Theory of Interlinked Rural Transactions." J. Public Econ. 20(1982):167-91.

Nalebuff, G., and J. E. Stiglitz. "Prices and Incentives: Towards a General Theory of Compensation and Competition." Princeton University Res. Memo. No. 293, 1982.

Newbery, D. M. G. "Risk Sharing, Sharecropping and Uncertain Labour Markets." Rev. Econ. Stud. 44(1977):585-94.

Rao, C. H. H. Technological Change and Distribution of Gains in Indian Agriculture. New Delhi, India: Macmillan \& Co., 1975.

Rudra, A. "Sharecropping Arrangements in West Bengal." Econ. Polit. Weekly, vol. 10, no. 39, 27 Sep. 1975.

Singh, I. "Small Farmers and the Landless in South Asia." Draft. Washington DC: The World Bank, 1984.

Stiglitz, J. E. "Incentives and Risk Sharing in Sharecropping." Rev. Econ. Stud. 61(1974):219-56. 
Copyright of American Journal of Agricultural Economics is the property of Agricultural \& Applied Economics Association and its content may not be copied or emailed to multiple sites or posted to a listserv without the copyright holder's express written permission. However, users may print, download, or email articles for individual use. 